\title{
What Matters for the Wellbeing of Mothers and Children in Material Hardship? Application of a Modified Indicator Framework
}

\author{
Leah Haines $^{1} \cdot$ Arthur Grimes $^{1,2}$ (D)
}

Accepted: 4 November 2021 / Published online: 28 November 2021

(c) The Author(s), under exclusive licence to Springer Nature B.V. 2021

\begin{abstract}
We examine determinants of subjective wellbeing (SWB) for mothers of dependent children in material hardship, using a modification of the New Zealand Treasury's Living Standards Framework (LSF) and data from the General Social Survey. We convert the LSF - an indicator dashboard-into a tool for prioritising social policies by placing SWB at the head of a hierarchy of wellbeing domains. Several determinants of these mothers' SWB conform to standard findings; however, two important differences stand out. One is the lack of a protective effect from employment on SWB for this group (unlike the protective effect for males). The other is a positive relationship between a mother's SWB and satisfaction with her own skills/knowledge; this effect is particularly strong for sole mothers in hardship, dominating any effect of qualifications on SWB. The analysis demonstrates both a practical use of a modified LSF, and the value of taking a gender-specific approach to analysing wellbeing.
\end{abstract}

Keywords Subjective wellbeing · Living Standards Framework · Mothers · Children · Material hardship

\section{Introduction}

The New Zealand government has adopted an overarching wellbeing approach to public policy (New Zealand Government, 2019). One priority of that approach is to improve child wellbeing (DPMC, 2019). The New Zealand Treasury (2018a) has developed a Living Standards Framework (LSF) modelled on the OECD's Better Life Index (OECD, 2011,

Disclaimer Access to the data used in this study was provided by Statistics New Zealand under conditions designed to keep individual information secure in accordance with requirements of the Statistics Act 1975. The opinions presented are those of the authors and do not necessarily represent an official view of Statistics New Zealand.

Arthur Grimes

arthur.grimes@motu.org.nz

1 Victoria University of Wellington, PO Box 600, Wellington 6140, New Zealand

2 Motu Economic and Public Policy Research, PO Box 24390, Wellington 6142, New Zealand 
2017) to underpin the wellbeing policy approach. The LSF, which is designed to apply to the whole population, includes 12 domains of current wellbeing plus four 'capitals' that are thought to underpin future wellbeing. However, there is no specification for how one might use the LSF indicators to analyse what matters for the overall wellbeing of the population at large or of population sub-groups.

We adapt the LSF to show how one might apply an indicator framework such as the LSF to analyse what matters for women in material hardship with dependent children. The health and wellbeing of mothers, particularly those in hardship, matters in its own right. The choice of this group is also warranted given the policy focus on child wellbeing and the literature which shows an intrinsic link between the wellbeing of mothers and the outcomes of their children (Dominick, 2018; Lister, 2005; Jaffee \& Poulton, 2006); Expert Advisory Group on Child Poverty, 2012). Hence our focus on mothers in hardship reflects three key factors: First, mothers play a significant role as the primary caregivers of most children in material hardship (Perry, 2019; Stats NZ, 2010). This is particularly true of mothers who are sole parents. Second, there is a substantial body of evidence about the impact of a mother's wellbeing on the life course outcomes of their children (Lister, 2005). Finally, survey data is available on the wellbeing of mothers where it isn't yet collected on their children. In this way mothers in hardship provide some insight into the lives of children in hardship, who are the target of priority government policy.

Mothers in material hardship are often the subject of government policy, particularly in the welfare system where parents who seek government assistance are subject to sanctions if they do not meet a number of social and work-based obligations (Work and Income, 2020). These policies may be underpinned by assumptions about what is in the best interests of mothers and their children. A key example is the assumption about the importance of paid employment and the "danger" of welfare dependency. This has been manifested in the efforts of successive governments (in New Zealand and elsewhere) to incentivise parents to work through rewards such as tax credits, or to force parents into work through financial sanctions for parents on a benefit. These moves reflect a view that people on a benefit "have a responsibility to prepare for and move into paid work" (Welfare Working Group, 2011).

In designing policy to improve child and family wellbeing, it is vital to test assumptions about what drives wellbeing in order to avoid unintended harm. To do so, we apply a modified version of the Treasury's LSF approach. Rather than looking at the cross-domain wellbeing of population groups without prioritising any particular domain(s), we use subjective wellbeing (SWB), based on a life satisfaction scale, as the proxy for overall wellbeing and measure the strength of effect of the other domains on it. This is consistent with the recommendations of Smith (2018) to elevate the place of SWB to stand above the 11 other domains, with those domains contributing to individuals' overall wellbeing.

The analysis demonstrates how an indicator framework such as the LSF can be used practically to better understand the wellbeing of sub-groups, such as mothers in hardship. We adopt a gender-sensitive approach to wellbeing measurement that could help avoid discrimination and biases caused by incorrect assumptions (Scott \& Masselot, 2018). This approach is different from other recent New Zealand analyses on the wellbeing of families which have looked at the distribution of wellbeing by family type (McLeod, 2018; Krassoi Peach \& Cording, 2018). These analyses have found that sole parents, and young Māori 
and Pacific ${ }^{1}$ mothers in particular, are at high risk of low multidimensional wellbeing due to structural factors (Krassoi Peach \& Cording, 2018).

The paper uses data from the New Zealand General Social Survey to investigate which of Treasury's other 11 domains of wellbeing have strong relationships with the life satisfaction of mothers in material hardship, whether employed or not employed, single or partnered. Mothers, in this paper, refers to women aged 15 and over with dependent children. Material hardship is defined here for practical purposes as those who score in the bottom quartile in the Ministry of Social Development's ELSI material wellbeing index. This measure is explained further later in the paper.

The paper begins by providing a background to the key issues, placing the wellbeing of children and their mothers in New Zealand's political and policy context, and reviewing relevant literature. The methods and data are described in Sect. 3 followed by presentation of our empirical results in Sect. 4. Section 5 discusses some policy implications of the paper both for wellbeing frameworks and for the welfare of mothers and children in hardship.

\section{Background and Literature}

\subsection{Child Wellbeing Focus}

The New Zealand Government has set a series of targets to reduce poverty and material hardship among children using measures specified in the Child Poverty Reduction Act (2018). ${ }^{2}$ In addition, its Child and Youth Wellbeing Strategy seeks to improve the overall wellbeing of New Zealand children and young people (DPMC, 2019). Before the Covid-19 emergency, $13.4 \%$ of all children were living in households experiencing material hardship and $20.8 \%$ of children were living in income poverty, using the main after-housing-costs measure in the Act (The Treasury, 2020). In order to address the factors affecting child and youth wellbeing, accurate gender-specific information about the drivers of wellbeing for those most at risk of material hardship will be vital. Treasury's analysis shows that men and women fare differently across different wellbeing domains (McLeod, 2018). Without a gender specific-analysis of the determinants of wellbeing when developing and implementing policy that affects families with children there is a risk that structural inequalities between women and men could be hidden or exacerbated (Masselot, 2015).

Gender-sensitive analysis is a particularly important consideration when developing policy for the welfare system. There is evidence that sole parents and their children were disproportionately impacted by the 2008 financial crisis due to the combined effects of the economic impact on lower income people and welfare reforms which targeted sole parents with new work and social obligations (Scott \& Masselot, 2018). In New Zealand, 84\% of sole parents with dependent children are women (Ministry for Women, 2018). ${ }^{3}$ In their systematic review of mandatory welfare to work programmes in five countries, including New

\footnotetext{
1 Māori are the indigenous population of New Zealand; the Pacific population are migrants (or descendants of migrants) from Pacific Island nations.

2 The Child Poverty Reduction Act specifies 10 distinct measures of child poverty, including measures related to income and material hardship. Given that New Zealand is a developed country, each of these measures can be interpreted as a relative (rather than absolute) poverty measure.

3 In our sample from the 2012 GSS, $81 \%$ of sole parents with dependent children are female.
} 
Zealand, Campbell et al.'s (2016) main finding was that the welfare reforms tended to lead to precarious low paid work for sole parents and a denial of control over the major decisions affecting their lives. Factors such as a lack of suitable social and welfare support and childcare risked such programmes being counterproductive to wellbeing.

The wellbeing of sole mothers is particularly relevant to policy efforts designed to improve wellbeing for children, as half of all New Zealand children experiencing material hardship live in sole parent homes (Perry, 2019). A New Zealand analysis of the wellbeing of sole parents, using the Living Standards Framework, shows they have distinctively low wellbeing compared with other groups of adults (McLeod, 2018). Another quantitative analysis of sole parents shows that Māori and Pacific mothers aged under 40 are particularly at risk of multi-dimensional disadvantage (Krassoi Peach \& Cording, 2018). This paper complements those analyses by analysing the determinants of wellbeing for the entire group of mothers in material hardship, together with specific sub-groups such as sole mothers in hardship.

\subsection{Life Satisfaction as a Measure of Wellbeing}

Surveyed life satisfaction, measured on a Likert scale, is a measure of subjective wellbeing which is frequently used as a proxy for overall wellbeing or utility (Layard, 2010; O’Donnell et al., 2014; Carver \& Grimes, 2019; Brown et al., 2012; Easterlin, 2001; Stiglitz et al., 2009). However, the use of subjective wellbeing as a measure of overall wellbeing is contentious. In particular, Sen is critical of a single focus on happiness measured as individual life satisfaction because people have been shown to adapt their preferences according to their experiences of life. His capabilities approach instead focuses on the freedoms people have to "lead the kind of life people have reason to value" (Sen, 1999; Bache $\&$ Scott, 2018). This thinking has led to the adoption of checklists of indicators to summarise multiple domains of wellbeing (Stiglitz et al., 2009; OECD, 2011). Despite these criticisms, there is evidence that life satisfaction has a positive relationship with other wellbeing metrics, such as health (Deaton, 2008) and revealed preference choices including migration decisions (Grimes et al., 2014; Grimes \& Wesselbaum, 2019).

Treasury (2018b) states that the LSF is based on Sen's capabilities approach although, in practice, the 12 domains are a collection of diverse outcomes that include SWB. We treat the LSF's 11 domains other than SWB as representing intermediate outcomes that contribute to overall SWB as measured by life satisfaction. This approach has the potential to identify the domains that most protect against or determine low subjective wellbeing amongst a particular population group. This understanding, in turn, can help prioritise policy interventions that will make the largest positive impact on that population group. In our case, the focal group is mothers and their children who are living in material hardship.

\subsection{The Connection Between Child and Maternal Wellbeing}

Evidence shows that the wellbeing and life prospects of children are intertwined with the health and wellbeing of their parents, particularly their mothers (Dominick, 2018; Wylie et al., 1999; Jaffee \& Poulton, 2006; Conger et al., 2002). In psychological literature and practice, the concept of family wellbeing is often seen as foundational to child wellbeing (Newland, 2015). Several reviews have identified how the stress of low income and economic hardship impact on a range of children's outcomes by affecting parent mental health, conflict between parents, and the interactions and conflict 
that occurs between parents and their children (Dominick, 2018; McLoyd, 1998; Conger et al., 2002). The impacts on children include impairments to their socioemotional functioning, as well as their cognitive and academic abilities, which can have life-long implications for their future wellbeing.

Research has shown a particular link between maternal mental health, parenting and child outcomes, and wellbeing (Jaffee \& Poulton, 2006). Evidence from Growing up In New Zealand, a longitudinal study of children born in 2009 and 2010, showed that material hardship was associated with significant increases in the likelihood of maternal depression and anxiety, and negative impacts on a baby's temperament by the time they were 9 months old (Dominick, 2018). These effects increased as the level of hardship rose. Material hardship, in that study, also increased the likelihood of families living in poor quality, damp and crowded households.

Research also indicates that the health and wellbeing of mothers has a greater impact on their children than that of fathers due to their proximity to each other, and the time mothers spend on caregiving, particularly in homes experiencing material hardship (Lister, 2005; Dominick, 2018). Mothers are significantly more likely than fathers to be the primary caregiver of children, spending on average three times as much time caregiving as fathers (Stats NZ, 2010). International research suggests they are also more likely to be the "manager" of family poverty in two-parent homes (Lister, 2005).

A New Zealand analysis of the wellbeing of sole parents, using the Living Standards Framework, shows they have distinctively low overall wellbeing across multiple domains compared with other groups of adults (McLeod, 2018). This may be because sole parents are more likely to experience material hardship (Rea et al., 2019), which in turn is a predictor of low subjective wellbeing (Carver \& Grimes, 2019). However, low multi-domain wellbeing is not experienced equally by all sole parents. Some groups, such as younger Māori and Pacific mothers, are much more at risk of multiple disadvantages than others (Krassoi Peach \& Cording, 2018). These mothers are more likely to be experiencing depression, anxiety, poor health and lower education-all of which have strong negative effects on children's outcomes (Jaffee \& Poulton, 2006; Wylie et al., 1999; Dominick, 2018; Krassoi Peach \& Cording, 2018). Research shows that mothers who regularly engage with the benefit system worry about the impact of such stresses on their children (Ministry for Women, 2018).

We take the approach that mothers in material hardship are the (often untapped) experts about their own and their children's health and wellbeing. They know more than anyone about the day to day challenges of managing low income, intergenerational disadvantage, racism, discrimination, and unaffordable housing while also raising the next generation. It is therefore important to base policies on the reported experiences of affected mothers. We do so using an official survey of social outcomes and experiences (the New Zealand General Social Survey), concentrating our analysis on mothers in hardship. An alternative approach, which we recommend but leave to future research, would be to involve mothers in a participatory, qualitative exercise that seeks their views on the domains and dimensions of wellbeing that are most important to them and their children (Waring, 2018). This is particularly important for Māori, Pacific and minority communities who have less individualistic notions of wellbeing. Either approach, based on mothers' own experiences, may test some of the public policy assumptions about what makes life better for New Zealand's most materially deprived women and their children. 


\subsection{Effects of Employment and Education on Life Satisfaction}

Policies that focus on assisting mothers in hardship frequently require or encourage mothers to undertake work and/or study. Because of this policy focus, we pay special attention to the impacts of employment and education on mothers' SWB. The importance of these two factors for wellbeing has previously been examined extensively for the general population but not for our focal group of mothers in hardship.

Evidence shows that one of the strongest negative impacts on life satisfaction is unemployment (Rea,et al., 2019; Brown et al., 2012; Carver \& Grimes, 2019; Clark, 2018). An analysis published alongside the 2012 General Social Survey, (the same survey used for this research) found unemployed people were three times as likely as others to report low life satisfaction (Stats NZ, 2012). This effect could be due to the positive impact of social esteem and relationships formed at work (Brown et al., 2012). It could also be because consumption, indicated by material hardship levels, is strongly predictive of life satisfaction (Carver \& Grimes, 2019) and material hardship is much less common among those whose main income source is paid work (Perry, 2019). For those in work, the literature also finds that one of the strongest positive associations with SWB comes from job satisfaction (Brown et al., 2012).

Research that tracked outcomes for people who had recently transitioned from welfare into work found a much less positive relationship between employment and overall wellbeing. For instance, an evidence review for the Welfare Expert Advisory Group (WEAG, 2019), a group established by government, reported that: transitions into employment are sometimes short lived; the quality and security of employment varies; people who move from benefit to work may only receive a modest increase in income; and there were contradictory findings on employment and parenting, including negative effects on children from casual childcare often associated with precarious work (WEAG, 2019). On average, the review found that employment had a positive effect on mental health of beneficiaries (this finding was not limited to parents) but that low paid and stressful workplaces may do the opposite. The report suggested that any policies that obliged beneficiary parents to work needed to be accompanied by support through financial incentives, childcare, and flexible arrangements that accounted for the age and needs of children. They also warned that an emphasis on sanctions had been reported by parents as a source of financial and psychological distress.

Evidence about the value of education on wellbeing is also mixed. A range of studies has failed to find a strong independent relationship. For example, Dolan et al. (2008) found that once factors such as higher incomes and better health (which may be related to higher education) were controlled for, the impact of education tended to disappear. A similar result has been found for New Zealand (Carver and Grimes, 2019) while contrary evidence is provided in (Brown et al., 2012). An evaluation of the experiences of New Zealand single parents studying at university through the training incentive allowance has found that the parents reported improvements in their overall wellbeing, and mental health, as a result of their study (Adamson, 2004). One gap in this literature, which we attempt to fill, is whether it is education per se that contributes to wellbeing (if indeed it does) or whether their wellbeing is more dependent on a person's satisfaction with their level of education and skills. No prior study that we are aware of has addressed this aspect. 


\section{Data and Methodology}

\subsection{Framework and Data Source}

A major focus of our study is to demonstrate a method to transform a national wellbeing indicator framework into a tool that can be used to prioritise social policies for a population group. Given that we use New Zealand data, our natural starting point is therefore the New Zealand Treasury's Living Standards Framework (LSF), an existing tool available for public policy wellbeing analysis. However, unlike the LSF model, we treat subjective wellbeing (measured as life satisfaction) as the proxy measure for overall current wellbeing, and hence as the dependent variable for our regressions. Life satisfaction is measured on a Likert scale so our estimates are obtained using ordered logistic regression. The main independent variables are the other 11 LSF domains which are treated as contributors to overall SWB. Conceptually, this approach is similar to that of the Australian Treasury's 2004 wellbeing framework (Australian Treasury, 2004).

We wish to examine which aspects of wellbeing have the strongest relationship to the SWB of mothers in material hardship. This group includes those who are single or partnered, in paid work or not employed. The choice to include all mothers in hardship reflects the heterogeneous nature of the group of children experiencing material hardship; for example, $60 \%$ of children in poverty have a parent who works, and about half of "poor" children come from two parent families (Perry, 2019). Our approach enables the identification of factors that might determine, or protect against, low life satisfaction among mothers raising children in hardship, after controlling for their demographic characteristics. We compare the results for mothers in hardship with results for all males, all females and all mothers to gauge whether there are differences across population sub-groups in the way that the 11 wellbeing domains relate to overall life satisfaction. We also differentiate within the group of mothers in hardship between those who are partnered and those who are not. These results indicate whether a 'one-size-fits-all' approach to interpreting wellbeing indicators is applicable or whether different weightings need to be applied in order to interpret the wellbeing of different population sub-groups.

The NZ General Social Survey 2012 (henceforth GSS) is our source of information on life satisfaction and it also provides data on a range of economic and social domains of wellbeing. The GSS measures life satisfaction using a five point scale on which individuals rank their satisfaction with their life, with 1 (very dissatisfied) being the lowest. It is particularly useful for our purposes since it includes questions covering all the domains that appear in the LSF. ${ }^{4}$

We use the survey data to measure the strength of the relationship for mothers in material hardship between life satisfaction and a range of other variables that fit within each of Treasury's other 11 wellbeing domains. The chosen indicators match those chosen by Treasury in the LSF in many cases, but in other domains Treasury's indicators have been swapped with indicators that better fit the empirical evidence about factors that influence the wellbeing of mothers in hardship.

The Treasury's other 11 LSF domains comprise: (1) Civic engagement and governance; (2) Cultural identity; (3) Health; (4) Housing; (5) Income and consumption; (6) Knowledge

\footnotetext{
4 The 2012 survey is the most recent GSS available for use outside of Stats NZ's confidential datalabs. It includes questions relevant to our study that were not repeated in subsequent social surveys.
} 
and skills; (7) Safety; (8) Social connections; (9) Environment; (10) Jobs and earnings; (11) Time use. These domains reflect those in the OECD's Better Life Index (OECD, 2011) with the addition of the cultural identity domain.

Several questions from the GSS were chosen as potential indicators to include for each domain. The full list of candidate questions in each domain is included as Table 5 in the Appendix. ${ }^{5}$ That table also lists the indicators included in the Treasury's initial version of the LSF (Treasury, 2018b). Differences arise due to the questions available in the 2012 set, and choices of alternative questions that are more relevant to the population of mothers in material hardship.

We utilise the variables listed in Table 5 in two ways in our analysis. First, we estimate the first principal component for each domain from the candidate variables (using polychoric correlations given the ordinal nature of the variables). We then regress SWB (i.e. life satisfaction) on the 11 principal components plus a set of demographic control variables. We do so for several sub-samples of mothers in hardship (including employed mothers, and partnered and sole mothers separately) plus for all mothers, all females, and all males.

Second, we narrow the list of variables down to one preferred variable per domain. To do so, we conducted an ordered logistic regression of SWB on the full set of control variables and each of the domain variables that are listed in Table 5 to identify the single variable within each domain that has the highest predictive power over SWB from within that domain for the sample of mothers in material hardship, which is our focal group. Having selected the representative question for each domain, we then include the 11 domain measures (plus demographic control variables) as explanatory variables in an ordered logistic regression with SWB as the dependent variable. We use the results from this regression to compare the relative importance of the selected variables from the 11 domains in determining SWB. We do so for the same sub-samples as in the first approach.

Based on our estimates, we then calculate the probability that a sole mother in hardship, who reports a high versus a low score for a specific domain, experiences high or low life satisfaction. These estimates demonstrate the materiality of effects of each domain for this population sub-group. We choose the sole parent sub-group for this analysis given that it is a particularly disadvantaged sub-group across multiple measures of wellbeing (McLeod, 2018).

We use the same set of demographic control variables for all our regressions, comprising: a dummy variable for sole parent status (with partnered being the omitted base category); dummy variables for having no dependent children, 2 dependent children, $3+$ dependent children (with 1 dependent child being the base); 8 separate age category dummies; and 7 separate ethnicity category dummies. Given that our focus is on partnered and sole mothers with dependent children, we report the estimates for the control variables for sole parent status and for dependent children; to keep the tables concise we do not report the separate age and ethnicity dummies. We note here, however, that the results for these latter variables are consistent with many prior findings in the literature. For instance, younger age is positively related to SWB, while identifying as Māori is negatively correlated with SWB for some, but not all, sub-samples.

\footnotetext{
5 A longer list of candidate variables was initially identified but we imposed a restriction that the candidate questions had to have at least 8000 responses (out of the full sample of 8455) to mitigate issues of selection bias.
} 
Table 1 Proportion of respondents reporting life satisfaction at each level (\% of each group)

\begin{tabular}{llllll}
\hline Life satisfaction & All & Males & Females & $\begin{array}{l}\text { Mothers not in } \\
\text { hardship }\end{array}$ & Mothers in hardship \\
\hline 1 & 1.1 & 0.9 & 1.2 & 0.5 & 2.1 \\
2 & 6.0 & 5.7 & 6.3 & 2.0 & 13.7 \\
3 & 8.4 & 9.1 & 7.8 & 5.5 & 14.3 \\
4 & 53.5 & 55.6 & 51.9 & 52.4 & 56.3 \\
5 & 31.1 & 28.8 & 32.9 & 39.7 & 13.6 \\
Observations & 8455 & 3709 & 4746 & 1016 & 670 \\
Chi-sq $(p$ value $)$ & & & 0.882 & 0.081 & $<0.001$ \\
\hline
\end{tabular}

$1=$ very dissatisfied, $2=$ dissatisfied, $3=$ neither satisfied nor dissatisfied, $4=$ satisfied, $5=$ very satisfied. A low Chi=sq (p-value) indicates that the distribution is significantly different from the male distribution

\subsection{Data}

The 2012 GSS is a Stats NZ sample survey of the population aged at least 15 years of age. It had a response rate of $78 \%$, with a target sample size of $\sim 8500$. Of those surveyed, 8455 answered the SWB question, so forming our full sample.

A majority of respondents report life satisfaction at a 4 or 5 on the 5-point scale; however the distribution differs across population sub-groups. Table 1 shows the distributions for each of five groups: the full sample (All), all males, all females, mothers not in hardship, and mothers in hardship. We include males as a comparator group in the analysis since prior analyses provide evidence that social and economic policy is often formulated to reflect the life circumstances of males rather than of other groups (Waring, 1988, 2018).

Our definition of material hardship is based on the Economic Living Standards Index (ELSI) which is included in the 2012 GSS. The full ELSI comprises a list of 25 essential items and household challenges ranging from access to shoes and fresh fruit and vegetables to difficulty paying for power, or needing to borrow money to make ends meet. A shorter version, called the ELSI 15, is used for the GSS. Carver and Grimes (2019) provide a full description of the ELSI and demonstrate that the ELSI measure is a better predictor of SWB than is the GSS income variable.

The reported chi-square test in Table 1 indicates that there is no significant difference in the distribution of life satisfaction for (all) males and (all) females. Females who are not in hardship have lower rates of poor life satisfaction and a higher rate of high life satisfaction than for males (with borderline statistical significance). Mothers who are in hardship unambiguously report poorer levels of life satisfaction than does the male group. In addition, they have materially higher rates of poor life satisfaction and a much lower rate of high life satisfaction than do mothers who are not in hardship. The question that we explore in our econometric analysis is what lies behind these differing life satisfaction distributions. 
Table 2 Principal component correlates of SWB for various population sub-groups

\begin{tabular}{|c|c|c|c|c|c|c|c|}
\hline & (1) & $(2)$ & (3) & (4) & $(5)$ & (6) & (7) \\
\hline Sex & Male & Female & Female & Female & Female & Female & Female \\
\hline Dependent children & All & All & Yes & Yes & Yes & Yes & Yes \\
\hline Hardship status & All & All & All & Hardship & Hardship & Hardship & Hardship \\
\hline Work status & All & All & All & All & Employed & All & All \\
\hline Partner status & All & All & All & All & All & Partnered & Sole \\
\hline \multicolumn{8}{|c|}{ First principal component of domain } \\
\hline $\begin{array}{l}\text { Civic engagement and govern- } \\
\text { ance }\end{array}$ & $1.123 * *$ & $1.170 * *$ & 1.091 & 1.057 & 0.821 & 1.171 & 1.102 \\
\hline Cultural identity & $1.311^{* *}$ & $1.332 * *$ & $1.278 * *$ & 1.108 & $1.487 *$ & 1.218 & 1.027 \\
\hline Health & $1.602^{* * *}$ & $1.387 * *$ & $1.542 * *$ & $1.548 * *$ & $1.551 * *$ & $2.330 * *$ & $1.283^{*}$ \\
\hline Housing & $1.276^{* * *}$ & $1.288 * *$ & $1.244 * *$ & $1.142^{*}$ & 1.230 & 0.997 & $1.266^{* *}$ \\
\hline Income and consumption & $1.645^{* * *}$ & $1.624 * *$ & $1.645^{* *}$ & $1.813 * *$ & $1.682 * *$ & $1.820 * *$ & $1.982 * *$ \\
\hline Knowledge and skills & $1.346^{* * *}$ & $1.342 * *$ & $1.353 * *$ & $1.284 * *$ & 1.259 & 1.130 & $1.344 * *$ \\
\hline Safety & $1.135^{* * *}$ & 1.075 & $1.191 *$ & 1.196 & 1.226 & 1.059 & 1.269 \\
\hline Social connections & $1.200 * *$ & $1.435 * *$ & $1.359 * *$ & $1.448 * *$ & $1.394 *$ & $1.468 * *$ & $1.455^{* *}$ \\
\hline Environment & $1.107 * *$ & $1.075 * *$ & 0.990 & 0.909 & $0.795 *$ & 0.820 & 0.993 \\
\hline Time & 1.011 & 0.999 & 0.996 & 0.996 & 1.068 & 1.170 & 0.905 \\
\hline Jobs and earnings & $1.091 *$ & $1.126 * *$ & 1.081 & 1.135 & 0.776 & 1.182 & 1.196 \\
\hline \multicolumn{8}{|l|}{ Control variables } \\
\hline Sole parent & 0.810 & $0.674 * *$ & $0.658 * *$ & 0.735 & 0.862 & & \\
\hline No dependent children & $0.523^{* *}$ & $0.759 *$ & & & & & \\
\hline 2 Dependent children & 1.009 & 1.029 & 0.972 & 1.004 & 1.184 & 0.789 & 1.119 \\
\hline 3+Dependent children & 0.992 & 1.045 & 1.015 & 1.305 & $2.643 *$ & 1.259 & 1.256 \\
\hline Age controls ( 8 categories) & Yes & Yes & Yes & Yes & Yes & Yes & Yes \\
\hline $\begin{array}{l}\text { Ethnicity controls ( } 7 \text { catego- } \\
\text { ries) }\end{array}$ & Yes & Yes & Yes & Yes & Yes & Yes & Yes \\
\hline Observations & 3464 & 4446 & 1538 & 654 & 306 & 305 & 349 \\
\hline Pseudo- $\mathrm{R}^{2}$ & 0.143 & 0.152 & 0.164 & 0.115 & 0.142 & 0.126 & 0.127 \\
\hline
\end{tabular}

Dependent variable is life satisfaction ( 5 point scale from 1: v. dissat. to 5 . v. sat.). In the headings, Dependent children $A l l$ includes respondents with and without dependent children (Yes indicates has dependent children); Hardship status $A l l$ includes those in and not in hardship; other headings are self-explanatory. All results are from ordered logistic regressions with odds ratios reported. Statistical significance denoted by: ${ }^{* *} p<0.01,{ }^{*} p<0.05$. The domain variable in each case is the first principal component (formed using polychoric correlations) of the stated domain. All estimates relate to GSS respondents at least 15 years of age

\section{Results}

Our first set of results, reported in Table 2, are those in which SWB is regressed on the first principal component derived from each of the 11 domains. In each case odds ratios are reported for the ordered logistic regressions. ${ }^{6}$ We report results for seven different

\footnotetext{
6 Given that this is an ordered logistic regression (i.e. with more than two Likert scale categories), the interpretation of the odds ratio $(O R)$ is that for a one unit change in the independent variable, the odds for cases in a group that is greater than $\mathrm{k}$ is $O R$ times those for cases in a group that is less than or equal to $\mathrm{k}$. In turn the odds are defined as $\mathrm{p} /(1-\mathrm{p})$ where $\mathrm{p}$ is the probability of being in the relevant group. Hence an odds ratio greater (resp. less) than one implies a positive (resp. negative) association between the independ-
} 
sub-samples: (i) all males; (ii) all females; (iii) mothers (i.e. females with dependent children); (iv) mothers who are in hardship; (v) mothers who are in hardship and who are employed; (vi) mothers who are in hardship and who are partnered; (vii) mothers who are in hardship and who are sole parents.

Nine of the 11 domains are significant for both males (column 1) and females (column 2); males' SWB is also significantly associated with Safety while neither sex exhibits a significant association with respect to Time. These commonalities, however, mask some important differences. For instance, Social connections has a much stronger association with SWB for females than for males, while the opposite is the case for Health. In addition, being a sole parent has a stronger association with poor SWB for females than for males.

Three domains have significant associations with SWB across all seven samples: Health, Income and consumption, and Social connections. The consistent importance of these three domains reflects the broader literature on the determinants of SWB (Clark, 2018). Notably, for the most deprived sub-sample, sole mothers in hardship, two other domains-Housing and Knowledge and skills-also have significant associations with SWB. The significance of other domains varies across sub-samples.

While establishing broad associations between the domains and SWB for different groups, the results in Table 2 may obscure relationships that are particularly important for our focal group of mothers who are in hardship. Our second approach concentrates on the variable in each domain that provides the strongest relationship with SWB for members of this group.

Appendix Table 6 presents summary statistics for the ordered logistic regressions of SWB on the full set of control variables and each of the domain variables listed in Table 5. For each domain, the variable with the highest explanatory power (conditional on the control variables) is presented in bold. In each case other than for Jobs and earnings, at least one category of the selected variable has a significant association (at the 5\% level or less) with SWB in the relevant regression. For Jobs and earnings neither being Unemployed nor being Not in the labour force has a significant association (relative to being Employed) with SWB for this group.

We nevertheless include labour force status as an explanatory variable in our regressions for two reasons. First, labour force status may be important for other sub-groups with whom we compare mothers in hardship. Second, it remains the best of the candidate variables in terms of its association with SWB for the group of mothers in hardship. We cannot include labour force status for the sub-group comprising employed mothers in hardship (since all these mothers are employed). For this group, we substitute another Jobs and earnings variable that is relevant only to those who are employed: "How do you feel about your employment arrangement?" (WORQ09). Inclusion of this variable enables us to test the relationship between satisfaction with work and overall SWB for mothers in hardship who are employed.

In addition to the lack of association between SWB and labour force status for mothers in hardship, one other result stands out. We find a much stronger relationship between SWB and a mother's satisfaction with her knowledge and skills than with her qualifications level. The effect of the variable measuring satisfaction with knowledge and skills is not

Footnote 6 (continued)

ent variable and SWB. Significance is reported relative to an odds ratio of 1 (i.e. a null hypothesis of no effect). 
Table 3 Specific domain variable correlates of SWB for various population sub-groups

\begin{tabular}{llllllll}
\hline & $(1)$ & $(2)$ & $(3)$ & $(4)$ & $(5)$ & $(6)$ & $(7)$ \\
\hline Sex & Male & Female & Female & Female & Female & Female & Female \\
Dependent children & All & All & Yes & Yes & Yes & Yes & Yes \\
Hardship status & All & All & All & Hardship & Hardship & Hardship & Hardship \\
Work status & All & All & All & All & Employed All & All \\
Partner status & All & All & All & All & All & Partnered Sole
\end{tabular}

CIVIC ENGAGEMENT and GOVERNANCE: Police treat all people fairly (HUMS2Q01_2: strongly agree)

$\begin{array}{llllllll}\text { Agree } & 0.756 * & 0.678 * * & 0.733 & 0.598 & 0.991 & 0.963 & 0.407 \\ \text { Neither agree nor disagree } & 0.646 * * & 0.687 * * & 0.805 & 0.850 & 1.257 & 1.011 & 1.054 \\ \text { Disagree } & 0.619 * * & 0.594 * * & 0.643 & 0.612 & 1.384 & 0.590 & 0.823 \\ \text { Strongly disagree } & 0.839 & 0.301 * * & 0.289 * * & 0.258^{*} & 0.619 & 0.128 & 0.381\end{array}$

CULTURAL IDENTITY: How easy is it to express identity (CULQ04: very easy)

$\begin{array}{llllllll}\text { Easy } & 0.801 * * & 0.686 * * & 0.612 * * & 0.707 & 0.627 & 0.676 & 0.682 \\ \begin{array}{l}\text { Sometimes easy, sometimes } \\ \quad \text { difficult }\end{array} & 0.666^{* *} & 0.762 * * & 0.706 * & 1.046 & 0.933 & 0.965 & 0.914 \\ \quad \begin{array}{llllll}\text { Difficult } \\ \text { Very difficult }\end{array} & 0.435 * * & 0.722 & 0.526 & 0.532 & 0.307 & 0.366 & 0.672 \\ & 1.027 & 0.542 & 1.344 & 1.970 & 0.019 * & 3.016 & 1.395\end{array}$

HEALTH: Feeling depressed or anxious (HEAQ05: none of the time)

$\begin{array}{llllllll}\text { All of the time } & 0.326^{* *} & 0.148^{* *} & 0.356 & 0.662 & 0.092 & 0.236 & 1.667 \\ \text { Most of the time } & 0.241^{* *} & 0.202^{* *} & 0.149^{* *} & 0.152^{* *} & 0.146^{* *} & 0.044^{* *} & 0.328^{*} \\ \text { Some of the time } & 0.436^{* *} & 0.363^{* *} & 0.346^{* *} & 0.380^{* *} & 0.333^{* *} & 0.192^{* *} & 0.506^{*} \\ \text { A little of the time } & 0.514^{* *} & 0.576^{* *} & 0.547^{* *} & 0.556^{* *} & 0.456^{*} & 0.406^{* *} & 0.734\end{array}$

HOUSING: How do you feel about where you are living (HOUQ01: very satisfied)

$\begin{array}{llllllll}\text { Satisfied } & 0.498^{* *} & 0.529 * * & 0.645^{* *} & 0.578^{*} & 0.842 & 0.668 & 0.649 \\ \text { No feeling either way } & 0.361^{* *} & 0.432^{* *} & 0.510^{* *} & 0.438^{*} & 0.641 & 0.528 & 0.380^{*} \\ \text { Dissatisfied } & 0.372 * * & 0.330^{* *} & 0.369^{* *} & 0.386^{* *} & 0.326^{*} & 0.351^{*} & 0.562 \\ \text { Very dissatisfied } & 0.246^{* *} & 0.163 * * & 0.190^{* *} & 0.189 * * & 0.295 & 0.633 & 0.081^{* *}\end{array}$

INCOME and CONSUMPTION: Material wellbeing (ELSIDV1, derived cardinal variable within GSS)
ELSI
$1.096 * * 1.092 * * 1.089 * * 1.097 * * \quad 1.065$
$1.105^{* *} \quad 1.113^{* *}$

KNOWLEDGE and SKILLS: How do you feel about your knowledge/skills/ability (KASQ01: very satisfied)

Satisfied

No feeling either way

$0.599 * * \quad 0.510 * * \quad 0.693 * * \quad 0.530 * *$

Dissatisfied

$\begin{array}{llll}0.407 * * & 0.410 * * & 0.469 * * & 0.590\end{array}$

0.925

1.061

$0.331 * *$

Very dissatisfied

$0.342 * * \quad 0.269 * * 0.302 * * 0.261 * *$

0.964

1.401

$0.283 * *$

$0.081 * * \quad 0.221 * \quad 0.167 * \quad 0.141^{*}$

$0.310 *$

$0.304 *$

$0.166 * *$

SAFETY: How safe do you feel walking home at night (SAFQ01E: very safe)
Safe
$0.783 * * 0.706 * * 0.710$
$0.407^{*}$
$0.115 * * \quad 0.296$
0.448
Unsafe
$0.789 * \quad 0.717 * 0.668$
$0.356^{* *}$
$0.098 * * \quad 0.246 *$
0.372
Very unsafe

$0.825 \quad 0.733 * 0.568 *$
$0.308 * *$
$0.119 *$
0.432
$0.160 * *$
Not applicable
$0.572 * * 0.648 * * 0.595$
$0.206 * * 0.097 *$
$0.197 *$
$0.204 *$

SOCIAL CONNECTIONS: How often have you felt isolated from others (SOCQ11: none of the time)

\begin{tabular}{llllllll} 
All of the time & $0.371^{* *}$ & $0.386^{* *}$ & $0.352^{*}$ & $0.288^{*}$ & $0.035^{* *}$ & 0.299 & $0.137 * *$ \\
Most of the time & $0.462^{* *}$ & $0.535^{* *}$ & 0.656 & $0.424^{*}$ & 0.411 & $0.281^{*}$ & 0.408 \\
Some of the time & $0.751^{*}$ & $0.588^{* *}$ & 0.768 & 0.911 & 0.773 & 1.795 & $0.508^{*}$ \\
A little of the time & 0.882 & $0.723^{* *}$ & 0.763 & 0.973 & 1.129 & 1.198 & 0.671 \\
\hline
\end{tabular}


Table 3 (continued)
(1)
(2)
(3)
(4)
(5)
(6)

(7)

ENVIRONMENT: How do you feel about lakes, harbours/etc (PHYQ12: very satisfied)

$\begin{array}{llllllll}\text { Satisfied } & 0.932 & 0.985 & 0.866 & 1.099 & 0.946 & 0.646 & 2.044 \\ \text { No feeling either way } & 0.614^{* *} & 0.686^{* *} & 0.825 & 1.161 & 1.085 & 0.755 & 2.098 \\ \text { Dissatisfied } & 0.936 & 0.860 & 0.573^{*} & 0.593 & 0.391 & 0.435 & 0.818 \\ \text { Very dissatisfied } & 0.938 & 1.008 & 1.072 & 0.957 & 0.440 & 1.435 & 1.264 \\ \text { Have not been to any } & 0.555 & 0.654 & 0.954 & 1.066 & 0.161 & 13.316 & 0.369 \\ \text { TIME: How much free time } & \text { (LEIQ01: right amount } & \text { of free time) } & & & \\ \text { Too much free time } & 0.695^{* *} & 0.651^{* *} & 0.673 & 0.583 & 0.564 & 0.408 & 0.537 \\ \text { Not enough free time } & 0.975 & 0.925 & 0.944 & 0.757 & 1.017 & 0.869 & 0.473 * * \\ \text { JOBS and EARNINGS: Labour force status (CORDV14: employed) } & & & \\ \text { Unemployed } & 0.562^{* *} & 1.379 & 1.368 & 1.353 & & 2.968 & 1.241 \\ \text { Not in the labour force } & 1.158 & 1.236^{* *} & 1.149 & 1.313 & & 1.439 & 1.394\end{array}$

How do you feel about employment arrangements (WORQ09: very satisfied)

Satisfied

0.685

No feeling either way

0.515

Dissatisfied

$0.293^{*}$

Very dissatisfied

1.644

Control variables

\begin{tabular}{|c|c|c|c|c|c|c|c|}
\hline Sole parent & 0.949 & $0.670 * *$ & $0.623^{* *}$ & $0.641^{*}$ & 0.782 & & \\
\hline No dependent children & $0.520 * *$ & $0.687 * *$ & & & & & \\
\hline 2 dependent children & 0.996 & 0.992 & 0.939 & 1.057 & $1.560 * *$ & 0.771 & 1.597 \\
\hline $3+$ dependent children & 0.983 & 1.090 & 1.071 & 1.637 & 4.233 & 2.098 & 1.786 \\
\hline Age controls (8 categories) & Yes & Yes & Yes & Yes & Yes & Yes & Yes \\
\hline $\begin{array}{l}\text { Ethnicity controls ( } 7 \text { catego- } \\
\text { ries) }\end{array}$ & Yes & Yes & Yes & Yes & Yes & Yes & Yes \\
\hline Observations & 3507 & 4513 & 1552 & 663 & 310 & 310 & 353 \\
\hline Pseudo- $\mathrm{R}^{2}$ & 0.164 & 0.185 & 0.195 & 0.169 & 0.215 & 0.210 & 0.214 \\
\hline
\end{tabular}

Dependent variable is life satisfaction (5 point scale from 1: v. dissat. to 5. v. sat.). In the headings, Dependent children All includes respondents with and without dependent children (Yes indicates has dependent children); Hardship status All includes those in and not in hardship; other headings are self-explanatory. All results are from ordered logistic regressions with odds ratios reported. Statistical significance denoted by: $* * p<0.01, * p<0.05$. Domain names are in bold capitals, followed below by shortened description of domain question with question code and base category in parentheses. Dummies for 'don't know/ don't answer' are included in regressions but not reported. All estimates relate to GSS respondents at least 15 years of age

commonly explored in other analyses which tend to use variables related to qualification level as the primary indicator of education or knowledge. ${ }^{7}$

In Table 3, the capitalised entry shows the domain name (from the LSF) and the subsequent entry shows the question with the available response options. The GSS question

\footnotetext{
7 One note of caution in interpreting this variable, and some other variables, is that the question relates to a self-assessment as does the dependent variable raising the potential for common method variance (Williams \& Brown, 1994). Helliwell and Huang (2010) note that the inclusion of other self-assessed variables in the regression (such as our inclusion of satisfaction with the environment) may help to mitigate this bias.
} 
number is shown in parentheses along with the omitted base group for that question. Subgroups are identical to those in Table 2 and estimates are again presented as odds ratios. Our discussion of results for these groups concentrates only on variables that are significant at the $5 \%$ level for at least one response category.

Across each of the sub-groups, having poor mental health, being dissatisfied with housing, having low material wellbeing, low feelings of safety, and social isolation are each associated with having lower SWB. We find a positive relationship between satisfaction with knowledge and skills and SWB, a result that is particularly strong for sole mothers. This relationship is weaker for mothers in employment suggesting that this group may be utilising some of their skills in the workplace. Two other noteworthy observations related to the group of employed mothers, are that a strong negative relationship exists between SWB and finding it very difficult to express cultural identity, and between SWB and being dissatisfied with employment arrangements. A further noteworthy finding is that the environment domain has no significant associations with SWB for any of the groups of mothers in hardship, though it does for (all) males, (all) females and (all) mothers.

Unemployment (relative to being employed) has a strong negative effect on the SWB of males but not for any of the female groups. By contrast, not being in the labour force ${ }^{8}$ is positively and significantly associated with SWB for females, but not males. These two labour force results are, of course, conditional on the other covariates included in the regressions. One of these covariates is the material standard of living (ELSI) which is positively correlated with employment. In further (unreported) regressions, we have omitted ELSI from the specifications. Once we do so, there is no longer a significant positive association of 'Not in the labour force' with SWB for (all) females; the significance of each of the other labour force categories across the various regressions does not change. Material living standards also contribute to other domains. If we omit all 10 other domains from the regressions, we observe a significant negative association of 'Unemployed' with SWB for each of (all) males and (all) females, but not for any other category; and a significant negative association of 'Not in the labour force' with SWB for each of (all) males, (all) females and (all) females with dependent children, but not for the other categories. The contrasts in results for the importance of labour force status between males and females illustrate the importance of taking a gendered perspective when it comes to analysing the correlates of SWB across different population groups. In addition, the differing results for females with different family and hardship circumstances show the importance of accounting for family and material wellbeing status when considering the determinants of SWB across population sub-groups.

Another contrast appears with the Time variable, in this case with respect to partnership status. Not having enough free time has a significant negative association with SWB for sole mothers who are in hardship but this relationship is much less apparent (and not significant) for any of the other groups. The proportion of respondents who report having not enough free time is similar across males (39\%) and females (41\%). However, the rates increase sharply for the groups with dependent children: $56 \%$ of all mothers do not have enough free time with this proportion rising to $68 \%$ for mothers in hardship who are employed. For sole mothers in hardship, the proportion with insufficient free time is $52 \%$, lower than for the other sub-samples with dependent children. Nevertheless, the estimated importance of feeling that they do not have enough free time for sole mothers in hardship

8 Not being in the labour force indicates that the individual is not employed and is not looking for work. 
Table 4 Probability of being in life satisfaction categories 1-3 based on best and worst values of seven domain variables

\begin{tabular}{|c|c|c|c|c|}
\hline \multirow[t]{3}{*}{$\begin{array}{l}\text { DOMAIN } \\
\text { Variable }\end{array}$} & \multicolumn{4}{|c|}{$\begin{array}{l}\text { Probability of being in LS categories } \\
1-3\end{array}$} \\
\hline & \multicolumn{2}{|c|}{$\begin{array}{l}\text { Sole mothers in } \\
\text { hardship }\end{array}$} & \multicolumn{2}{|c|}{ All females } \\
\hline & Best & Worst & Best & Worst \\
\hline $\begin{array}{l}\text { HEALTH } \\
\text { Feeling depressed or anxious (HEAQ05) }\end{array}$ & 0.30 & 0.48 & 0.11 & 0.30 \\
\hline $\begin{array}{l}\text { HOUSING } \\
\text { How do you feel about where you are living (HOUQ01) }\end{array}$ & 0.27 & 0.67 & 0.10 & 0.32 \\
\hline $\begin{array}{l}\text { INCOME and CONSUMPTION } \\
\text { Material wellbeing (ELSIDV1) }\end{array}$ & 0.24 & 0.53 & 0.16 & 0.38 \\
\hline $\begin{array}{l}\text { KNOWLEDGE and SKILLS } \\
\text { How do you feel about your knowledge/skills/ability (KASQ01) }\end{array}$ & 0.21 & 0.77 & 0.10 & 0.27 \\
\hline $\begin{array}{l}\text { SAFETY } \\
\text { How safe do you feel walking home at night (SAFQ01E) }\end{array}$ & 0.21 & 0.48 & 0.13 & 0.25 \\
\hline $\begin{array}{l}\text { SOCIAL CONNECTIONS } \\
\text { How often have you felt isolated from others (SOCQ11) }\end{array}$ & 0.29 & 0.62 & 0.13 & 0.24 \\
\hline $\begin{array}{l}\text { TIME } \\
\text { How much free time (LEIQ01) }\end{array}$ & 0.28 & 0.39 & 0.14 & 0.15 \\
\hline
\end{tabular}

The probabilities are calculated based on the estimates in columns (7) and (2) of Table 3. The proportion of sole mothers in hardship with dependent children in LS categories 1-3 is 0.35 . The proportion of all females in LS categories $1-3$ is 0.15

indicates that those who are in this situation are likely to be particularly time poor relative to other groups. ${ }^{9}$

It is important to interpret the materiality of the estimated effects of each of the domains on life satisfaction. We do so by focusing on the group who suffer the lowest levels of SWB, sole mothers in hardship. We concentrate on the seven domains that are shown, in Table 3, to have a significant association with SWB for this group. Table 4 presents the probability of a person who reported the 'best' or the 'worst' levels of wellbeing in each of these seven domains, also reporting low life satisfaction (columns 1 and 2 respectively). Low life satisfaction here means being in level 1 (very dissatisfied), 2 (dissatisfied) or 3 (neither dissatisfied nor satisfied). For the material living standards variable (ELSIDV1), 'worst' is taken to be those at the 5th, i.e. highly deprived, decile of the distribution for sole mothers in hardship while 'best' is taken to be at the 25 th percentile of the population (i.e. on the cusp of being considered not in hardship by our measure). For leisure time (LEIQ01), 'worst' is "not enough time" and 'best' is "the right amount of time. In each case, other covariates are held at their average level. ${ }^{10}$ The table lists each domain (in capitals) and a shortened description of the relevant question (plus its GSS question number). For comparison purposes, columns 3 and 4 show corresponding probabilities for (all)

\footnotetext{
9 It is interesting to note that having too much free time has a significantly negative association with SWB for all groups, significantly so for the all male and all female groups.

10 This means, for instance, that our notional comparator has the average age and 'average ethnicity' of the sample. The probabilities in Table 4 are calculated using the margins option in Stata.
} 
females based on the results in column (2) of Table 3.Several results for sole mothers in hardship stand out. First, those who report being "very dissatisfied" with their knowledge and skills have a $77 \%$ probability of also reporting low life satisfaction, while those who are most satisfied with their skills have only a $21 \%$ chance of reporting low SWB, a difference of 56\% points (p.p.) in the likelihood of reporting poor SWB. Second, those who are very dissatisfied with their housing situation have a 40 p.p. increase in their probability of having low life satisfaction (compared with those who are very satisfied with their housing). Third, those who often feel isolated have a 33 p.p. increase in their probability of low life satisfaction (compared with people who do not feel isolated) while feeling very unsafe walking home raises the probability of poor SWB by 27 p.p. Moving from low to high status for health and time availability make smaller, but still material, contributions to the likelihood of having poor SWB (18 p.p. and 11 p.p. respectively). A shift in material wellbeing from a very low level to the cusp of the hardship category reduces the chance of being in poor SWB by 29 p.p.; naturally a move out of hardship (e.g. to the population median material wellbeing level) would have an even larger effect. ${ }^{11}$

The comparison of sole mothers in hardship with (all) females shows that the probability of a sole mother in hardship having low life satisfaction is greater than for the (all) female group for each ('best' and 'worst') category of every variable. Furthermore, the effect on SWB of being in the 'worst' relative to the 'best' category is in every case greater for sole mothers in hardship than it is for (all) females. For instance, a sole mother in the 'worst' housing category is $40 \%$ points (p.p.) more likely to have low life satisfaction than is a sole mother in the 'best' housing category, whereas this gap is only 22 p.p. for the (all) female group. These results indicate that, as well as conducting gender-sensitive analyses, policymakers need to consider SWB impacts according to family structure and hardship status.

\section{Discussion and Conclusions}

Improving the wellbeing of mothers in hardship should be an important public policy goal in its own right and is also a critical step in improving the wellbeing of children. Our analysis-using a modified version of the New Zealand Treasury's Living Standards Framework (LSF) - identifies the key wellbeing domains most relevant to improving the overall SWB of mothers in hardship. The analysis for this group confirms several established relationships between SWB and various contributors to wellbeing; in particular, we see strong relationships between SWB and each of housing, mental health, material wellbeing, safety, and social connections.

Two findings, however, stand out both because they do not conform with much of the international literature on wellbeing for the general population, and because they challenge certain policy settings that affect the wellbeing of mothers in hardship.

First, SWB of mothers in hardship is not systematically improved by employment. ${ }^{12}$ This finding departs from much of the international and New Zealand literature for the

\footnotetext{
11 We do not report the effects of a larger shift in material wellbeing since a counterfactual that exceeds the hardship cut-off lies outside the support for this variable in the regression estimated for this population sub-group.

12 The analysis presents average effects for each group. It is likely that some mothers experience positive impacts on their wellbeing from employment while others do not.
} 
wellbeing of the general population which finds a strong protective effect from employment though in our analysis this effect is limited to males. For employed women experiencing material hardship, the most significant relationship in the jobs and earnings domain was a negative impact on SWB from dissatisfaction with their employment arrangements.

Our findings do not contradict evidence about the value of paid work as a way to improve income (since living standards are controlled for in the regressions). They do suggest, however, that more research is needed to understand the importance of both the quality and suitability of paid work on the wellbeing of mothers in material hardship, and for mothers of dependent children in general (Seaford, 2018; Scott \& Masselot, 2018). This observation is supported by research into welfare to work programmes which found that such schemes can be counterproductive to wellbeing due to the lack of childcare, social and welfare support, and suitable, stable work (Campbell et al., 2016). New Zealand evidence stresses the importance of work obligations being flexible enough to allow parents to meet their children's needs at important stages in their development (WEAG, 2019). The impact of work quality on wellbeing was also the focus of a large Dutch study which found employees who report high effort and low reward in their work show elevated risks of emotional exhaustion and low physical health (de Jonge et al., 2000). Another finding from the cultural identity domain may be relevant to questions about the importance of quality work on wellbeing. Here a negative relationship was found between SWB and the feeling that it was "very difficult" for employed mothers in hardship to express their cultural identity.

In New Zealand, women comprise $60 \%$ of minimum wage employees and are more likely to be under-employed and under-utilised (Ministry for Women, 2018). If they are also receiving a main benefit, working mothers face high levels of benefit abatement that can make the financial return on work marginal (WEAG, 2019). Furthermore, employed women take on a disproportionate share of unpaid household and caregiving work when compared with men (Stats NZ, 2010). ${ }^{13}$ Assumptions about the value of employment and the dangers of "welfare dependency" have been cited by champions of welfare reform in several New Zealand governments. The 2011 welfare reforms introduced "a stronger work focus" designed to reduce welfare dependency, described as being "in line with modern social norms" (Welfare Working Group, 2011). These reforms required sole parents to be available for part-time work when their youngest child turned 5 years old. This was subsequently reduced to age 3 (Work and Income, 2020). This focus on work as being important for family wellbeing also underpins the Working for Families (WFF) package of tax credits in 2004. WFF provided weekly payments for each child, conditional on parents undertaking paid work for a minimum number of hours each week (Maharey, 2004). ${ }^{14}$

The question of whether the work incentives in the WFF package, or the work obligations of the welfare reforms, resulted in better wellbeing for children and their families does not appear to have been addressed by past governments. However, research has found that the 2011 welfare reforms had a disproportionate impact on women, sole parents, and Māori and Pacific peoples (Scott \& Masselot, 2018). Scott and Masselot criticise a "gender neutral" approach to measuring and designing social policy which fails to account for the lives of women. This critique is supported by the 2019 Welfare Expert Advisory Group which warned that if there were to be positive impacts from welfare to work programmes

\footnotetext{
13 There has been no time use survey in New Zealand since 2010 despite calls that this information is vital for addressing questions such as those analysed in this paper (Waring, 2018).

14 In response to the Covid19 crisis, from July 2020 the minimum work hours requirement has been removed.
} 
these would "require supportive accompanying policies such as the availability of in-work financial incentives and affordable centre-based early childhood education and out-ofschool care and recreation services (WEAG, 2019). Together these findings underscore the importance of a gender (and a culture) specific analysis of wellbeing when designing and measuring the impact of social policy. Without such an analysis, policy risks undermining the wellbeing of particular groups, such as mothers in material hardship, and could be discriminatory (Scott \& Masselot, 2018).

A second key finding with respect to wellbeing in our study is that satisfaction with knowledge and skills is strongly correlated with subjective wellbeing for all groups, but in particular for sole mothers in material hardship. The relationship is starkly illustrated in Table 4 in which sole mothers in material hardship who report being "very dissatisfied" with their skills and knowledge are estimated to have a $77 \%$ probability of also reporting low life satisfaction compared with just $21 \%$ for those who are very satisfied with their knowledge and skills. The importance of this variable is of particular interest as there is no precedent for any similar variable being used in the international literature. The variable has a much stronger relationship with SWB than any of the other variables tested in the knowledge and skills domain including qualifications levels (included as an indicator in the LSF). ${ }^{15}$

The importance of (dis)satisfaction with knowledge and skills suggests that many sole mothers in hardship (and others) may harbour an ambition for a better life through education. Further work is needed to understand what mothers perceive to be the impediments to improving their knowledge and skills. Levels of maternal education have a significant impact on education and other life course outcomes of children (Wylie et al., 1999; Magnuson, 2007). Hence programmes that make higher level education accessible for sole parents could be an effective intervention to improve mothers' wellbeing, and outcomes for children. One such intervention in New Zealand is the Training Incentive Allowance (TIA) which, until 2009, provided financial support to sole parents, and some other beneficiaries, to enable them to undertake study including at tertiary level. The settings for the TIA were changed in 2009 to limit access to those studying at the equivalent of secondary school level (Haines, 2009). This change affected about 4000 students who were planning to enrol in higher level study including nursing and teaching. An evaluation of the TIA prior to the change in settings found that university level study was common for sole parent beneficiaries using the allowance, and useful for gaining employment (Adamson, 2004). Of importance for this research, the evaluation found that recipients' happiness and mental health improved as a result of their study. Access to the TIA for higher level study was reinstated in the New Zealand Government's 2021 Budget.

\footnotetext{
15 Again we caveat this observation by noting that the magnitude of the estimated effect may be inflated by common method variance although the inclusion of other self-reported satisfaction measures as independent variables helps to mitigate this potential source of bias.
} 
At a methodological level, we demonstrate how an existing wellbeing indicator framework - the New Zealand Treasury's Living Standards Framework-can be adapted to make a tool to help prioritise social policy initiatives for certain population sub-groups. The key modification is to consider all 11 domains other than SWB, as contributors to the overall wellbeing of individuals, as proxied by SWB. By incorporating a gender-sensitive analysis, our approach shows that factors which protect the wellbeing of certain parts of the population, such as the importance of paid employment for males' SWB, do not necessarily improve life satisfaction for mothers, particularly those experiencing hardship. The modified framework also reveals that the life satisfaction of these mothers can be deeply impacted by feelings of dissatisfaction with their knowledge and skills. This suggests that interventions to provide better education opportunities for these mothers-rather than forcing them into employment—could be useful for improving their wellbeing as well as that of their children.

In addition to showing how a modified indicator framework can be used to identify effective policy interventions for a specific group, our analysis highlights the counterfactual: Paying insufficient attention to the unique wellbeing needs of particular population groups risks undermining their wellbeing even when the policy rhetoric is couched in terms of promoting wellbeing for all.

\section{Appendix}

See Tables 5 and 6. 


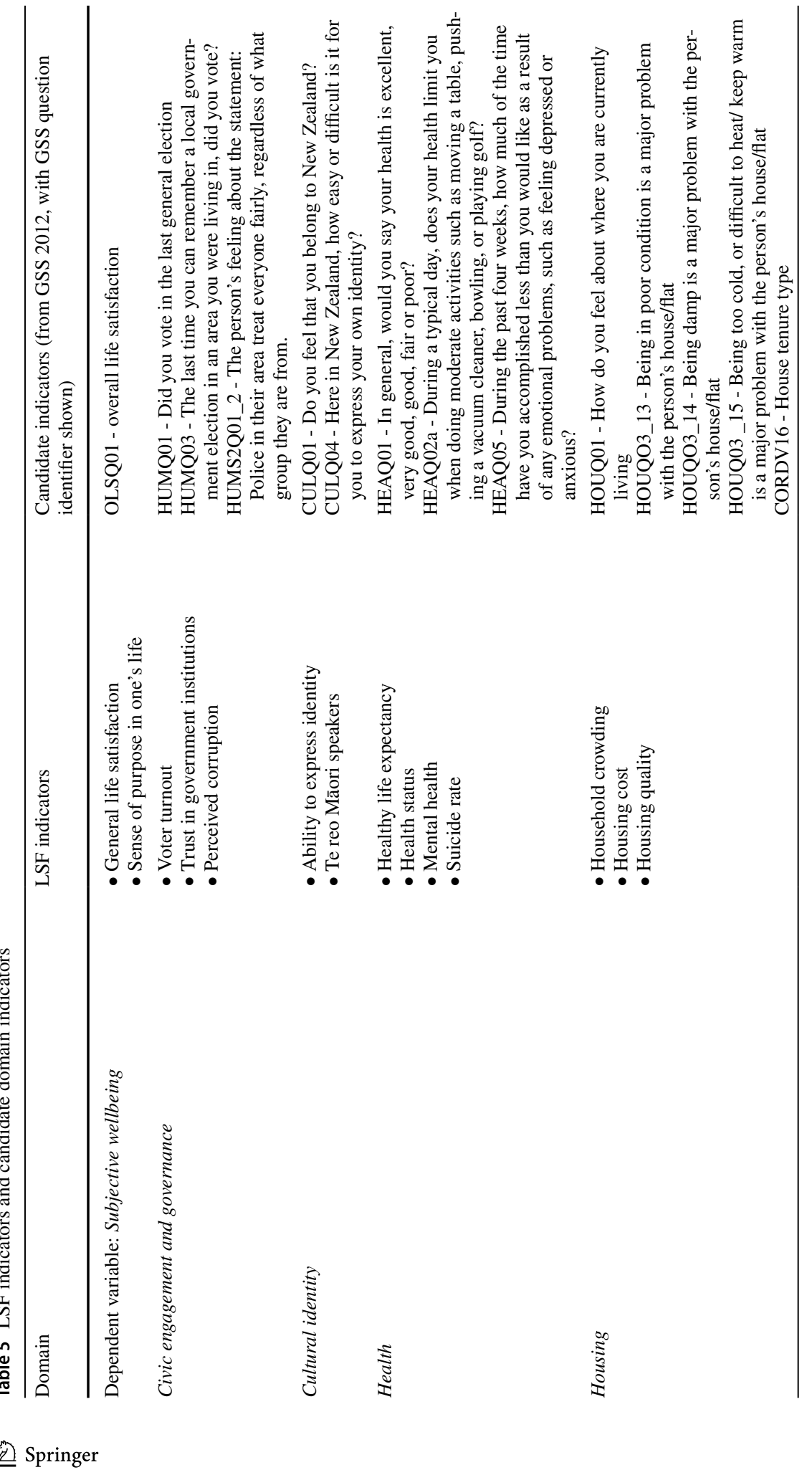









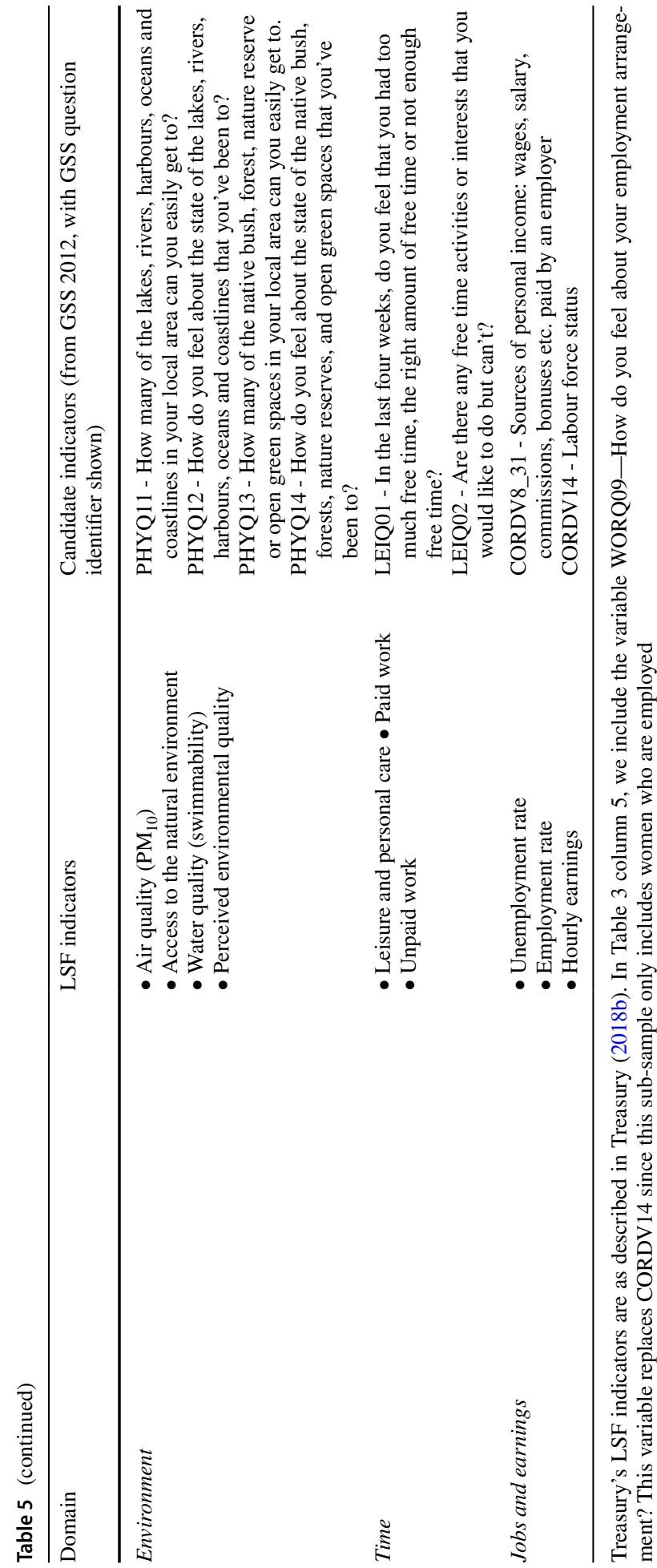


Table 6 Candidate indicators explanatory power

\begin{tabular}{|c|c|c|c|}
\hline Domain & $\begin{array}{l}\text { Candidate indicators } \\
\text { (see Appendix Table } 5 \text { for definitions) }\end{array}$ & Pseudo- $\mathrm{R}^{2}$ & Observations \\
\hline Civic engagement and governance & $\begin{array}{l}\text { HUMQ01 } \\
\text { HUMQ03 } \\
\text { HUMS2Q01_2 }\end{array}$ & $\begin{array}{l}0.0265 \\
0.0254 \\
0.0342\end{array}$ & $\begin{array}{l}669 \\
669 \\
669\end{array}$ \\
\hline Cultural identity & $\begin{array}{l}\text { CULQ01 } \\
\text { CULQ04 }\end{array}$ & $\begin{array}{l}0.0247 \\
0.0366\end{array}$ & $\begin{array}{l}669 \\
669\end{array}$ \\
\hline Health & $\begin{array}{l}\text { HEAQ01 } \\
\text { HEAQ02a } \\
\text { HEAQ05 }\end{array}$ & $\begin{array}{l}0.0591 \\
0.0252 \\
0.0882\end{array}$ & $\begin{array}{l}670 \\
670 \\
670\end{array}$ \\
\hline Housing & $\begin{array}{l}\text { HOUQ01 } \\
\text { HOUQO3_13 } \\
\text { HOUQO3_14 } \\
\text { HOUQ03_15 } \\
\text { CORDV16 }\end{array}$ & $\begin{array}{l}0.0463 \\
0.0294 \\
0.0273 \\
0.0304 \\
0.0270\end{array}$ & $\begin{array}{l}669 \\
669 \\
669 \\
669 \\
670\end{array}$ \\
\hline Income and consumption & $\begin{array}{l}\text { ELSQ08 } \\
\text { ELSIDV1 }\end{array}$ & $\begin{array}{l}0.0392 \\
0.0633\end{array}$ & $\begin{array}{l}669 \\
670\end{array}$ \\
\hline Knowledge and skills & $\begin{array}{l}\text { CORDV15 } \\
\text { KASQ01 }\end{array}$ & $\begin{array}{l}0.0308 \\
0.0446\end{array}$ & $\begin{array}{l}670 \\
670\end{array}$ \\
\hline Safety & $\begin{array}{l}\text { SAFQ01E } \\
\text { SAFQO2 }\end{array}$ & $\begin{array}{l}0.0404 \\
0.0252\end{array}$ & $\begin{array}{l}669 \\
669\end{array}$ \\
\hline Social connections & $\begin{array}{l}\text { SOCQ05 } \\
\text { SOCQ10 } \\
\text { SOCQ11 } \\
\text { SOCDV6 } \\
\text { HUMQ05 }\end{array}$ & $\begin{array}{l}0.0262 \\
0.0328 \\
0.0579 \\
0.0360 \\
0.0273\end{array}$ & $\begin{array}{l}669 \\
669 \\
669 \\
669 \\
669\end{array}$ \\
\hline Environment & $\begin{array}{l}\text { PHYQ11 } \\
\text { PHYQ12 } \\
\text { PHYQ13 } \\
\text { PHYQ14 }\end{array}$ & $\begin{array}{l}0.0273 \\
0.0339 \\
0.0300 \\
0.0306\end{array}$ & $\begin{array}{l}668 \\
663 \\
668 \\
657 \\
\end{array}$ \\
\hline Time & $\begin{array}{l}\text { LEIQ01 } \\
\text { LEIQ02 }\end{array}$ & $\begin{array}{l}0.0307 \\
0.0291\end{array}$ & $\begin{array}{l}669 \\
669\end{array}$ \\
\hline Jobs and earnings & $\begin{array}{l}\text { CORDV8_31 } \\
\text { CORDV14 }\end{array}$ & $\begin{array}{l}0.0251 \\
0.0257\end{array}$ & $\begin{array}{l}670 \\
670\end{array}$ \\
\hline
\end{tabular}

In each case all control variables that appear in Tables 2 and 3 are also included. Candidate variable in each domain with highest explanatory power is highlighted in bold in the table. Pseudo- $\mathrm{R}^{2}=0.0244$ for an equation that includes only the control variables (observations $=670$ ) 
Acknowledgements We thank two referees of this journal for helpful comments on an earlier version of this paper.

\section{Declarations}

Conflict of interest The authors declare that they have no conflict of interest.

\section{References}

Adamson, C. (2004). Phase 2 evaluation of the training incentive allowance. Centre for Social Research and Evaluation Te Pokapü Rangahau Arotake Hapori, MSD

Australian Treasury. (2004). Policy advice and Treasury's wellbeing framework. Economic Roundup Winter. Australian Treasury.

Bache, I., \& Scott, K. (2018). Wellbeing in politics and policy. In I. Bache \& K. Scott (Eds.), The politics of wellbeing (pp. 1-22). Palgrave Macmillan.

Brown, D., Woolf, J., \& Smith, C. (2012). An empirical investigation into the determinants of life satisfaction in New Zealand. New Zealand Economic Papers, 46, 239-251

Campbell, M., Thomson, H., Fenton, C., \& Gibson, M. (2016). Lone parents, health, wellbeing and welfare to work: A systematic review of qualitative studies. BMC Public Health, 16, 1-10.

Carver, T., \& Grimes, A. (2019). Income or consumption: Which better predicts subjective wellbeing? Review of Income and Wealth, 65(S(1), 256-280

Clark, A. (2018). Four decades of the economics of happiness: Where next? Review of Income and Wealth, 64(2), 245-269

Conger, R. D., Wallace, L., Sun, Y., Simons, R. L., Loyd, V. C., \& Brody, G. H. (2002). Economic pressure in African American families: A replication and extension of the family stress model. Developmental Psychology, 38(2), 179-193

de Jonge, J., Bosma, H., Peter, R., \& Siegrist, J. (2000). Job strain, effort-reward imbalance and employee well-being: A large-scale cross-sectional study. Social Science and Medicine, 50, Issue (9), 1317-1327.

Deaton, A. (2008). Income, health, and well-being around the world: Evidence from the gallup world poll. Journal of Economic Perspectives, 22(2), 53-72

Dolan, P., Peasgood, T., \& White, M. (2008). Do we really know what makes us happy? A review of the international literature on the factors associated with subjective wellbeing. Journal of Economic Psychology, 29, 94-122

Dominick, C. (2018). Association of material hardship with maternal and child outcomes: Technical report of cross-sectional analysis of nine-month. Wellington: Ministry of Social Development. Retrieved from https://doi.org/https://www.msd.govt.nz/about-msd-and-our-work/publications-resources/resea $\mathrm{rch} /$ material-hardship-maternal-and-child-outcomes/association-of-material-hardship.html

DPMC. (2019). The child and youth wellbeing strategy. Department of Prime Minister and Cabinet.

Easterlin, R. A. (2001). Income and happiness: Towards a unified theory. The Economic Journal, 111(473), 465-484.

Expert Advisory Group on Child Poverty. (2012). Solutions to child poverty in New Zealand: Evidence for action. Office of the Children's Commissioner.

Grimes, A., Oxley, L., \& Tarrant, N. (2014). Does money buy me love? Testing Alternative Measures of National Wellbeing. In McDaid, D., \& Cooper, C. (eds.). Economics of wellbeing, volume 5 of wellbeing: A complete reference guide (pp. 49-82). Wiley-Blackwell.

Grimes, A., \& Wesselbaum, D. (2019). Moving towards happiness. International Migration, 57(3), 20-40

Haines, L. (2009). Govt axe destroys dreams. Retrieved from New Zealand Herald: https://www.nzherald. co.nz/nz/news/article.cfm?c_id=1\&objectid=10585365

Helliwell, J., \& Huang, H. (2010). How's the job? Well-being and social capital in the workplace. Industrial and Labor Relations Review, 63(2), 205-227

Jaffee, S., \& Poulton, R. (2006). Reciprocal effects of mother's depression and children's problem behaviours from middle childhood to early adolescence. In A. Huston \& M. Ripke (Eds.), Developmental contexts in middle childhood: Bridges to adolescence and adulthood (pp. 107-129). Cambridge University Press. 
Krassoi Peach, E., \& Cording, J. (2018). Multiple disadvantage among sole parents in New Zealand. Social Policy Evaluation and Research Unit.

Layard, R. (2010). Measuring subjective well-being. Science, 327, 534-535.

Lister, R. (2005). Women's and children's poverty: Making the links. Women's Budget Group.

Magnuson, K. (2007). Maternal education and children's academic achievement during middle childhood. Developmental Psychology, 43(6), 1497-1512

Maharey, S. (2004). Working for families: Putting commitment into action: Speech. Retrieved from Beehive.govt.nz. https://doi.org/https://www.beehive.govt.nz/speech/working-families-putting-commi tment-action

Masselot, A. (2015). Gender implications of the right to request flexible working arrangements: Raising pigs and children in New Zealand. New Zealand Journal of Employment Relations, 39(3), 59-71.

McLeod, K. (2018). Our people: Multidimensional wellbeing in New Zealand. The Treasury.

McLoyd, V. C. (1998). Socioeconomic disadvantage and child development. American Psychologist, 53 , 185-204

Ministry for Women. (2018). Insights from mothers. Ministry for Women, Minitanga mā ngā Wāhine.

Newland, L. (2015). Family and child well-being. Clinical Psychology, 19, 3-14.

New Zealand Government. (2019). Wellbeing budget. New Zealand Government.

O’Donnell, G., Deaton, A., Durand, M., Halpern, D., \& Layard, R. (2014). Wellbeing and policy. Legatum Institute.

OECD. (2011). How's life? Measuring wellbeing. OECD better life initiative. OECD Publishing.

OECD. (2017). How's life? 2017: Measuring well-being. OECD Publishing.

Perry, B. (2019). The material wellbeing of New Zealand households: Trends and relativities using nonincome measures, with international comparisons. Ministry of Social Development.

Rea, D., Anastasiadis, S., Benny, V., Chokkanathapuram, A., Lee, W., Smith, C., \& Vandenbroucke, B. (2019). Measuring the living standards of people receiving income-tested main benefits. Working paper. Ministry of Social Development

Scott, K., \& Masselot, A. (2018). Skivers, strivers and thrivers: The shift from welfare to wellbeing in New Zealand and the United Kingdom. In I. Bache \& K. Scott (Eds.), The politics of wellbeing (pp. 253-277). Pulgrave MacMilllan.

Seaford, C. (2018). Is wellbeing a useful concept for progressives? In I. Bache \& K. Scott (Eds.), The politics of wellbeing (pp. 97-120). Palgrave Macmillan.

Sen, A. (1999). Development as freedom. Oxford University Press.

Smith, C. (2018). Treasury living standards dashboard: Monitoring intergenerational wellbeing. Kōtātā Insight.

Statistics New Zealand. (2019). Wellbeing statistics 2018. Retrieved from Stats NZ. https://doi.org/ https://www.stats.govt.nz/information-releases/wellbeing-statistics-2018

Stats NZ. (2010). Caring for children: Findings from the 2009/10 Time Use Survey. Statistics New Zealand.

Stats NZ. (2012). Key facts, NZ General Social Survey: 2012. Statistics New Zealand.

Stiglitz, J. E., Sen, A. K., \& Fitoussi, J. P. (2009). Report by the commission on the measurement of economic performance and social progress. Commission on the Measurement of Economic Performance and Social Progress.

Treasury. (2018a). Our people, our country, our future. The living standards framework: Introducing the dashboard. New Zealand Government.

Treasury. (2018b). Our people, our country, our future. The living standards framework: Background and future work. New Zealand Government.

The Treasury. (2020). Child Poverty Report, impact of Covid19. New Zealand Government.

Waring, M. (1988). San Francisco, CA: Harper \& Row. Also published as Counting for nothing: What men value and what women are worth. If women counted: A new feminist economics. Allen \& Unwin in association with the Port Nicholson Press.

Waring, M. (2018). Still counting for nothing. Bridget Williams Books.

WEAG. (2019). Obligations and Sanctions Rapid Evidence Review Paper 8: Work obligations for sole parents and outcomes for children. Welfare Expert Advisory Group.

Welfare Working Group. (2011). Reducing long-term benefit dependency: Recommendations. Welfare Working Group.

Williams, L., \& Brown, B. (1994). Method variance in organizational behavior and human resources research: Effects on correlations, path coefficients, and hypothesis testing. Organizational Behavior and Human Decision Processes, 57(2), 185-209

Work and Income. (2020). Sole Parent Support obligations. Retrieved from Work and Income: Te Hiranga Tangata: Sole Parent Support obligations 
Wylie, C., Thompson, J., \& Lythe, C. (1999). Competent children at 8: Early education and schools. New Zealand Council for Educational Research.

Publisher's Note Springer Nature remains neutral with regard to jurisdictional claims in published maps and institutional affiliations. 